\title{
Retinoblastoma cT0 TNM Finding v7
}

National Cancer Institute

\section{Source}

National Cancer Institute. Retinoblastoma CTO TNM Finding v7. NCI Thesaurus. Code C88753.

Retinoblastoma with no evidence of a primary tumor. (from AJCC 7th Ed.) 